\title{
Investigation into the microwave power absorption in tissues
}

\author{
Raad Hamdan Thaher', Heba Hadi Ali², Isam Salah Hameed ${ }^{3}$ \\ ${ }^{1,2}$ Electrical Engineering Department, University of Al-Mustansiriyah, Iraq \\ ${ }^{3}$ Electronic Engineering Department, University of Diyala, Iraq
}

\begin{tabular}{l}
\hline \hline Article Info \\
\hline Article history: \\
Received Jan 21, 2019 \\
Revised Jun 6, 2019 \\
Accepted Jun 28, 2019 \\
\hline
\end{tabular}

Keywords:

Free-space

Microwave power absorption

Tissues, moisture content

X-band

\begin{abstract}
In this paper, the behavior of different tissues to microwave signal is presented. Beef, lamb, and fat were taken as tissue samples. Moisture content, tissue thickness, and distance between transmit antenna and receive antenna were the main parameters to be investigated. Therefore, three types of tissues were tested as soaked, normal, and dried. Moreover, each individual sample was prepared in five thicknesses $(1 \mathrm{~mm}-5 \mathrm{~mm})$. The objectives of this paper is to discuss and determine the power absorption when each sample is tested under microwave signals. The experimental results declared the soaked tissue as the most power absorbing state when compared to the other two cases (normal and dried) for the same thickness value. It has also been found that the microwave power absorption is directly proportional to smaple thickness. Besides, the relationship between the microwave power absorption and distance between transmit and receive antennas was concluded to be directly proportional. With the aid of two techniques represented by an insertion transmission method and free-space transmission method, this paper presented an insight about the behavior of real tissues under the effect of microwave signals.
\end{abstract}

Copyright $(2019$ Institute of Advanced Engineering and Science. All rights reserved.

\section{Corresponding Author:}

Heba Hadi Ali,

Electrical Engineering Department, University of Al-Mustansiriyah, Baghdad, Iraq.

Email: engheh@gmail.com

\section{INTRODUCTION}

The rationale beyond the excessive studying microwave power absorption effect on human beings along with other creatures in recent decades, belongs to the extreme application of such waves in our daily life. Therefore, the form of electromagnetic radiation (EMR) has been increased due to the wide spread use of electrical and electronic devices in which electromagnetic field are common. However, the great service of such devices come in parallel with their dangerous effects on living tissues. Therefore, microwave sensors were developed to sense the behavior of such materials when exposed to microwaves [1].

The topic of absorbing electromagnetic power in highly lossy biological tissues is of importance to be intensively under investigation. For instance, the wide use of mobile phones has led to an important arousal regarding possible expected risks that might result from intensive mobile phones usage especially when facts come to analyze the head as the main power absorber [2]. It is worth mentioning that tissue damage can be set as a function of tissue type, microwave power density, operating frequency, and specific absorption rate. For example, the more moisture is the tissue the more microwave power is absorbed. Also, the period of exposure to electromagnetic fields has a great impact on tissue damage level [3].

In this paper, microwave power absorption investigation into real tissues of beef, lamb, and fat is presented. The investigation seeks Moisture content, tissue thickness, and distance between transmit antenna and receive antenna as the main parameter to be investigated. The study is based on testing all samples by using two schematic circuit design represented by an insertion transmission technique and free-space transmission technique. In the first technique, tissue size is finely designed to fit waveguide dimensions while the other 
technique uses larger sample dimensions as it will be tested in free-space. Results from this study provided an important information and presented an insight about the relation between microwave power absorption and moisture content, thickness, distance between transmit antenna and receive antenna [4].

\section{LITERATURE SURVEY}

Studies on power absorption in tissues have been found to search different aims. In 2004, a research on electromagnetic estimation regarding the power absorption in highly losses mediums was presented. Upon this study, prototype models of a highly losses material were gained to give an important insight into electromagnetic power absorption estimations [5]. In 2005, R. Zaridze took the side of investigating the relation between the thermal effect and the microwave power absorption amount which provided information about the RF power exposure effect on live tissue as well as its correlation to the temperature rise [6].

In 2006, Roman K. and et al presented an investigation of mice tissues in a term of an in vivo study where the mice are anesthetized during measurements. Results has come to show that young mice experience low levels of energy absorption compared to mature mice [7]. In 2007, another study presented an investigation of microwave energy absorption in living tissues in order to provide information about the best way of eliminating the possible attenuation that might affect the power transfer between the transmitter and the receiver of the biomedical implant $[8,9]$.

In 2010, Gheorghe G. et al. presented a study about the effect of microwave fields on the performance of the thyroid gland. In their study, the thermal rise caused by the long exposure to microwave radiation is put under assessment especially for such a vital organ that is highly exposed to microwave radiation [10]. Another contribution was published by A. M. Medhat and et al., in which they explored the microwave power absorption within different parts of the human body in order to make use of it in noninvasive glucose monitoring (NGM) [11].

In the literature of Pradip k. Datta, it was concluded that the contamination of microwave energy has a main effects on human health to a point that makes it highly considerable since tissues with high moisture experience more power absorption than that of the normal tissue. Therefore, the tissue itself can be regarded as a function of the microwave power density [12]. It is worth mentioning that some researchers used another types of antennas by which measuring the wireless Wi-Max and WLAN purposes are achieved. For instance, P-shaped Microstrip antenna, Elliptical Microstrip Patch Antenna, Dual band Microstrip antenna, and diamond patch antenna were to be able to cover a band of $2.3 \mathrm{GHz}-18 \mathrm{GHz}$. Therefore, the effect of such $\mathrm{GHz}$ should also be under research especially when the human lives tissues is probably an absorber candidate [13-17]. Consequently, in 2018 David C. et al. took the part of making an investigation to the mechanism of absorbing the energy for microwave signals of more than $10 \mathrm{GHz}$ and their interaction with human body-antenna. It was found that for frequencies above $24 \mathrm{GHz}$, the reactive near field provide less power absorption than the case of frequencies below $6 \mathrm{GHz}$ [18].

\section{MATERIALS AND METHODS}

In order to successfully obtain the materials of this study, beef and lamb meat as well as the fat of the sheep were chosen to be the tested tissues. The sizes of tested samples were prepared in two different dimensions according to two different measurement techniques. In the first technique, which is the inserted transmission method, the sample size is cut to be as the size of the waveguide cross sectional area in order to ensure a complete fit to its surface. On the other hand, the second size is prepared to be suitable with the freespace transmission method which requires larger sample size that should cover the horn antenna front size for better signal transmitting.

\section{MICROWAVE MEASUREMENTS}

\subsection{Transmission Methods}

Two-transmission methods were applied within this work. Firstly, an insertion transmission method is used to test the small size samples. In this method, the challenge of the necessary accurate sample preparation was avoided by setting up the sample to cover all the cross-sectional area of the waveguide instead of focusing on the cavity size. This will ensure that the transmitted signal would pass through the tissue with no probability of any leakage. Secondly, Free-space transmission method was used to test large size samples. This method supports a wide band of frequency ranges and it is regarded as an easy installation method as well as non-necessity for complicated sample preparation [19].

The first system is the insertion transmission method. This system includes a signal generator with a microwave oscillating output of $(8.5-12.5) \mathrm{GHz}$ range of frequencies. This oscillator is connected to a 
variable attenuator which is used for power controlling and level sensing. Next to the attenuator a waveguide for signal directing is connected and then a power meter is connected for power measurements. The sample was inserted between the waveguide and the power meter. Figure 1 shows a photograph of the experimental setup.

The second system is the free space transmission method. The system equipment of the transmitting side includes a signal generator represented by a Gunn diode oscillator which is negatively biased by a range of dc voltage from $(-7 \mathrm{~V}$ to $-10 \mathrm{~V})$. The oscillator provides an $\mathrm{x}$-band range of frequencies from (8.5 to 10.5) GHz. This Gunn is connected to an isolator which transmits microwave or radio frequency power in one direction only providing a protection procedure by isolating the input side from the conditions of the output side. Next to the isolator, a variable attenuator is connected and then the transmitted horn antenna is set up for signal transmitting.

On the receiver side another horn antenna is used to capture the transmitted signal which is then directed through a waveguide in order to measure it by a special power meter device. The holder of the sample was made from wood for better minimizing to the unwanted reflections. The distance between the transmitting antenna and the receiving antenna was set to be variable distance. It is worth mentioning that the distance between the transmitter station and the receiver station was accurately changed by using a sliding technique through which the various distance steps are smoothly achieved. The various distances are necessary in order to include the near field and far-field considerations. Figure 2 shows a photograph of the experimental setup.

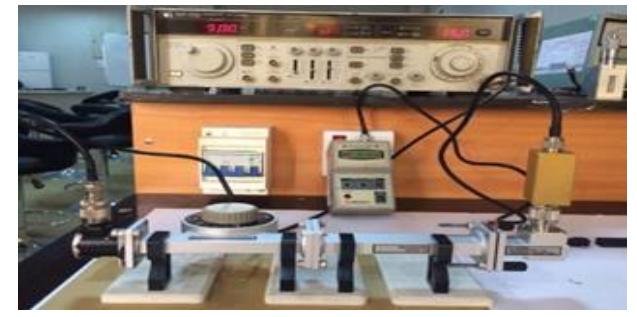

Figure 1. First system photograph

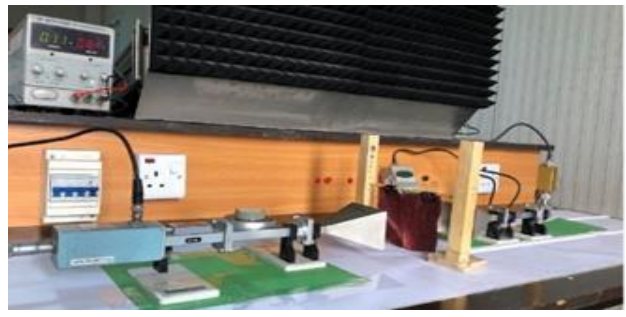

Figure 2. Second system photograph

\subsection{Power Absorption Measurements}

In the first system, measurements are performed without inserting material under test (MUT), then with the existence of MUT. This procedure is followed to test meat tissue samples ( beef and lamb) for different ratios of monisture content as well as fat tissue samples before and after inserting them between waveguide and power meter. A schematic diagram of measurement setup is shown in Figure 3.

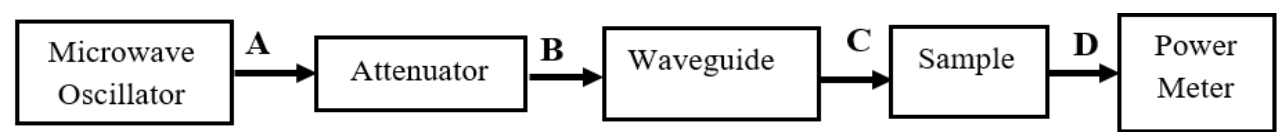

Figure 3. Schematic diagram of the measurement setup

Before testing any sample, the process is implemented by setting up the transmitter and the receiver as shown in Figure 1 where no sample is located. From Figure 3, point A represents the value of the microwave signal at that moment and it is given by:

$$
v=v_{\circ} e^{j \omega t}
$$

Where $v_{\circ}$ is the Maximum voltage in volt and $\omega$ is the angular frequency (rad).

The signal after the attenuator at point $\mathrm{B}$ will be:

$$
v=k_{1} v_{\circ} e^{j \omega t}, \text { for } k_{1}<1
$$

Where, $k_{1}$ represents the effect (attenuation) of the attenuator. At point $\mathrm{C}$, the signal will be affected by the waveguide. 


$$
v=k_{1} k_{2} v_{\circ} e^{j \omega t} \quad, \text { for } k_{2} \ll 1
$$

Where, $k_{2}$ is the effect (attenuation) of the waveguide, and it is given by (4):

$$
k=k_{1} k_{2}
$$

Therefore, $v$ can be written in terms of (5). Shown below:

$$
v=k v_{\circ} e^{j \omega t}
$$

At point $\mathrm{D}$, the received signal is related and affected by the meat (sample). Generally, the value of the signal at point $\mathrm{D}$ can be written in the form below:

$$
v=k v_{\circ} e^{j \omega t} e^{-\gamma_{m} \ell}
$$

Where $\ell$ is the thickness of sample in $(\mathrm{mm})$ and $\gamma$ is the propagation constant (in per meter) of the medium. $\gamma$ is given (7) below:

$$
\gamma=\alpha+j \beta
$$

Where $\boldsymbol{\alpha}$ represents the attenuation constant or attenuation factor of the medium in $(\mathrm{Np} / \mathrm{m})$ or $(\mathrm{dB} / \mathrm{m})$ and $\boldsymbol{\beta}$ refers to the phase constant or wave number that is given in (8). Below:

$$
\beta=2 \pi / \lambda \quad \mathrm{rad} / \mathrm{meter}
$$

With $\boldsymbol{\lambda}$ as the wavelength in (meter) and $\boldsymbol{\gamma}_{m}$ as the meat propagation constant.

By substituting the value of propagation constant of (7), $v$ can be written in terms of (9) as shown below:

$$
v=k v_{\circ} e^{j \omega t} e^{-\left(\boldsymbol{\alpha}_{m}+\boldsymbol{j} \boldsymbol{\beta}_{m}\right) \ell}
$$

In order to estimate the value of the power absorption, the absolute value of the sent and receivd power is recorded for the comparing calculations with the specific sample inserted in the way of the transmitted power. Hence, $\left(\mathrm{P}_{\mathrm{abs}}\right)$ or the amount of attenuation $(\alpha)$ can be written in terms of $(10)$ :

$$
P_{a b s}=\alpha=P_{r 1}-P_{r 2}
$$

Where $P_{a b s}$ is the power absorption, $P_{r l}$ is the received power without sample, and $P_{r 2}$ is the received power with sample [19].

Similarly, the second system measurements are performed according to the procedure of the first system with the installation of the Schematic diagram shown in Figure 4 where MUT is inserted between transmitter and receiver antennas. Hence, signal at point A and B of Figure 4 is described by (1) and (2). However, the received signal at point $\mathrm{C}$ is related and affected by air (free space). Therefore, the value of the signal at this can be written in the general form of (11):

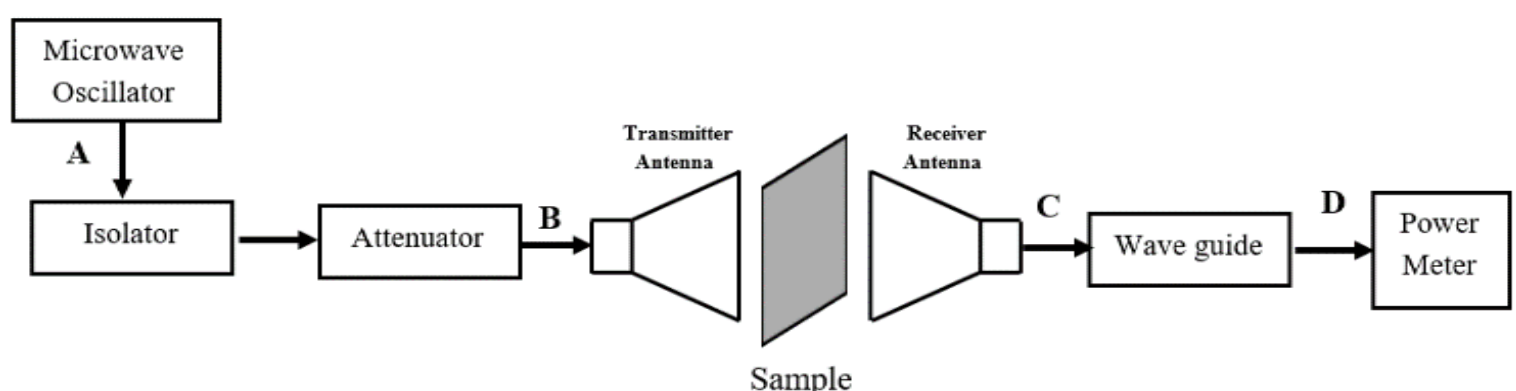

Figure 4. Schematic diagram of the measurement setup 


$$
v=k_{1} v_{\circ} e^{j \omega t} e^{-\alpha_{a}}
$$

Where $\boldsymbol{\alpha}_{a}$ is the attenuation of air with a very low value. As the signal takes it way toward point D of Figure 4, it will be well represented in (12) below:

$$
v=k_{1} k_{2} v_{\circ} e^{j \omega t} e^{-\alpha_{a}}, \text { for } k_{2} \ll 1
$$

With $k_{l} k_{2}$ written as one constant symbol $k$, (13) cn be written as follows:

$$
v=k v_{\circ} e^{j \omega t} e^{-\alpha_{a}}
$$

In the case of insertion samples between antennas, the received signal at point $\mathrm{C}$ is related and affected by sample thickness according to (14) shown below:

$$
v=k_{1} v_{\circ} e^{j \omega t} e^{-\alpha_{a}} e^{-\ell \gamma_{m}}
$$

Then at point $\mathrm{D}$, the signal is given by (15):

$$
v=k_{1} k_{2} v_{\circ} e^{j \omega t} e^{-\alpha_{a}} e^{-\ell \gamma_{m}}
$$

By substituting (4) and (7), $v$ can be written in terms of (16) shown below:

$$
v=k v_{\circ} e^{j \omega t} e^{-\alpha_{a}} e^{-\left(\boldsymbol{\alpha}_{m}+j \boldsymbol{\beta}_{m}\right) \ell}
$$

\section{RESULTS AND DISCUSSION}

Results are taken for each case of meat (beef and lamb) for different ratios of moisture as (soaked, normal and dried) as well as FAT tissues. Based on two measurement methods which are the insertion transmission method, and the free space transmission method and for range of sample thicknesses and microwave frequencies. It was found that the most power being absorbed is in the case of the soaked sample whether it was beef or lamb tissues. In first system, curves of Figure 5, 6, 7, and 8 show that the amount of power absorption is directly proportional to the MUT thickness and the most power absorption occurs at the case of soaked beef when compared to the other cases. Besides, the curves show that the amount of power absorption in fat is very low due to its low water contents.

The experimental results are applied to a computer package in order to express the attenuation in terms the sample thickness and it is expressed by:

$$
p_{a b s}=\alpha=c_{0}+c_{1} \ell^{1}+c_{2} \ell^{2}+c_{3} \ell^{3}+c_{4} \ell^{4}
$$

The coefficients $\left(c_{0}, c_{1}, c_{2}, c_{3}\right.$, and $\left.c_{4}\right)$ depend on the properties of samples (dielectric constant, and conductivity ) and the moisture content.

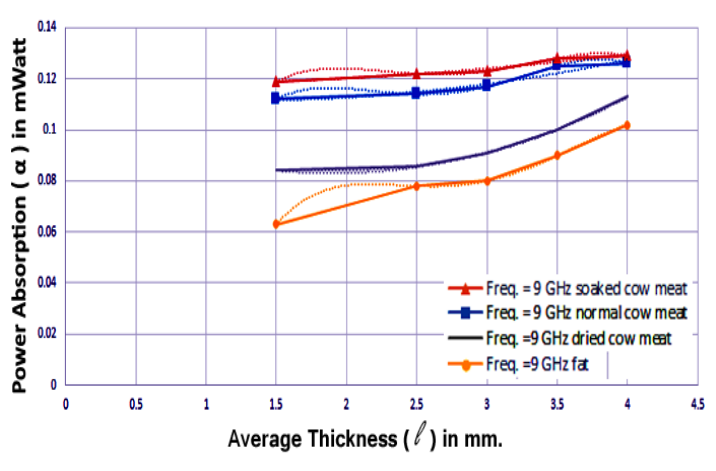

Figure 5. Power absorption for beef and fat at $9 \mathrm{GHz}$

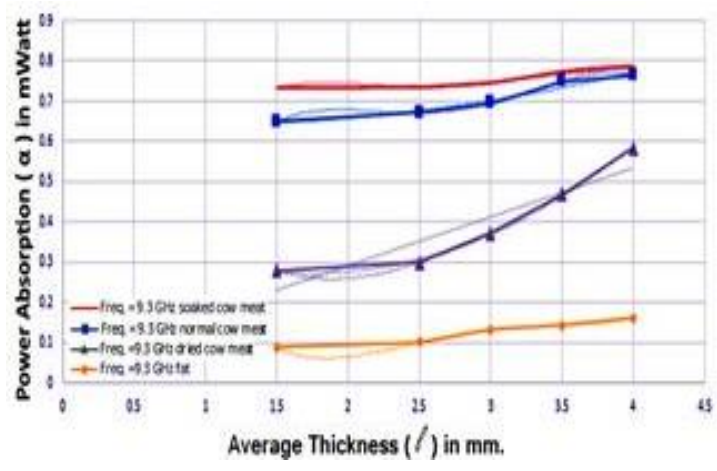

Figure 6. Power absorption for beef and fat at $9.3 \mathrm{GHz}$ 


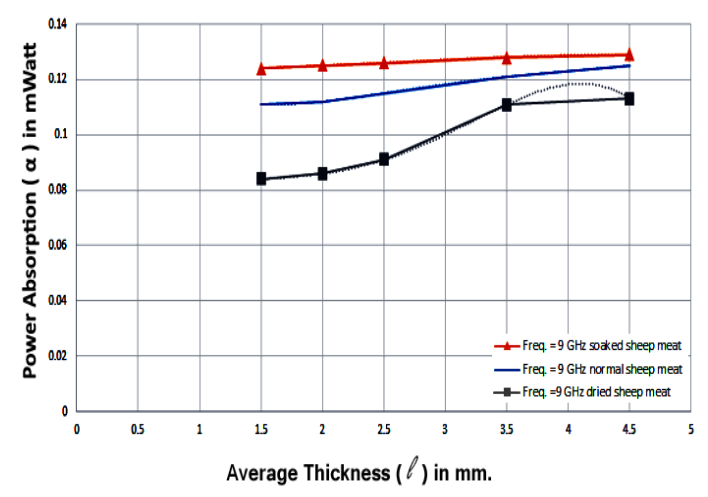

Figure 7. Power absorption for lamb at $9 \mathrm{GHz}$

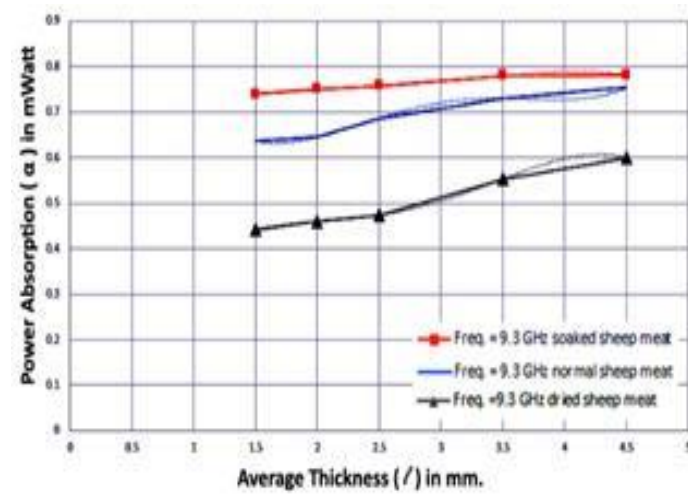

Figure 8. Power absorption for lamb at $9.3 \mathrm{GHz}$

In the second system, the curves of Figure 9 to Figure 16 show that the power absorption is affected by the distance between the transmitter antenna and receiver antenna where the amount of power absorption is increased as the distance increases.

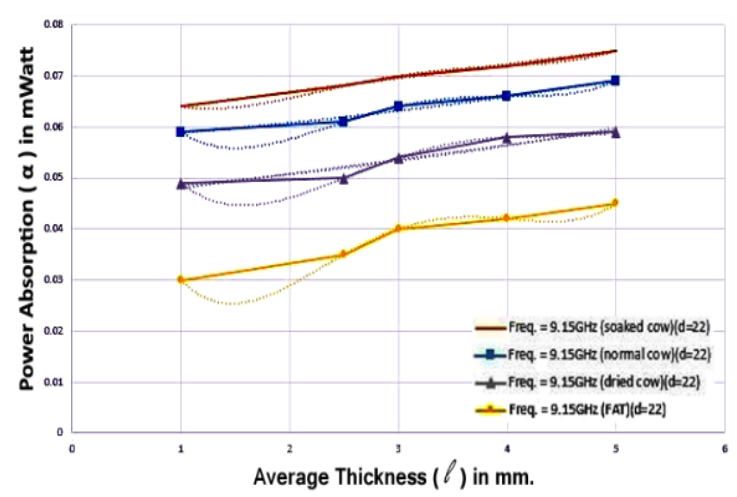

Figure 9. Power absorption for beef and fat at $9.15 \mathrm{GHz}$ and $\mathrm{d}=22 \mathrm{~cm}$

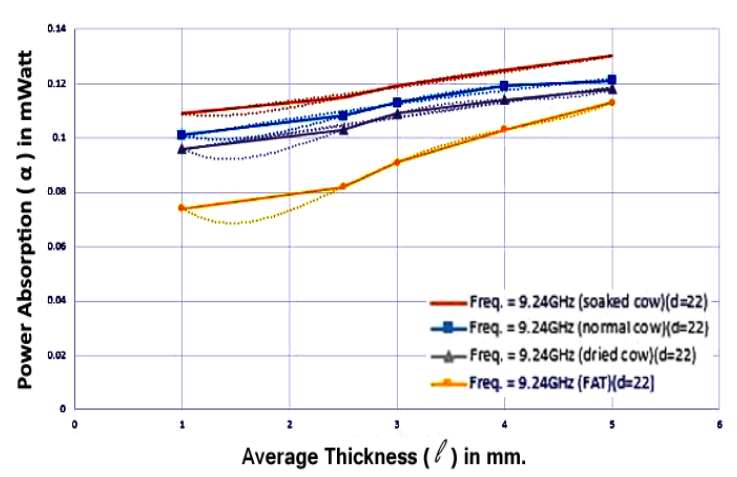

Figure 11. Power absorption for beef and fat at $9.24 \mathrm{GHz}$ and $\mathrm{d}=22 \mathrm{~cm}$

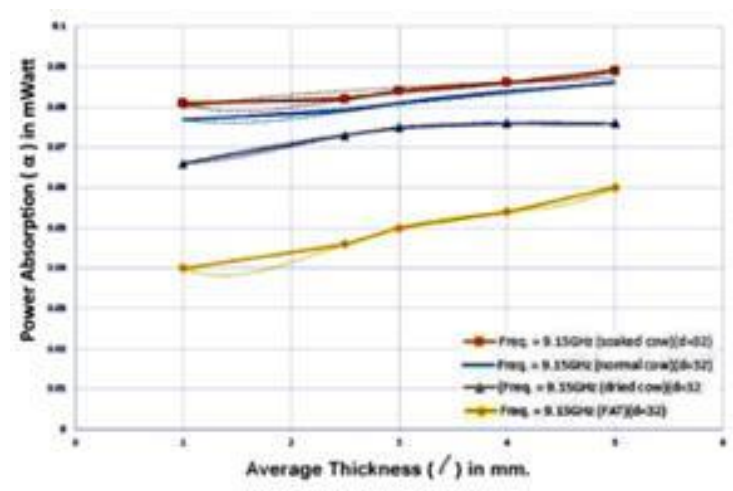

Figure 10. Power absorption for beef and fat at $9.15 \mathrm{GHz}$ and $\mathrm{d}=32 \mathrm{~cm}$

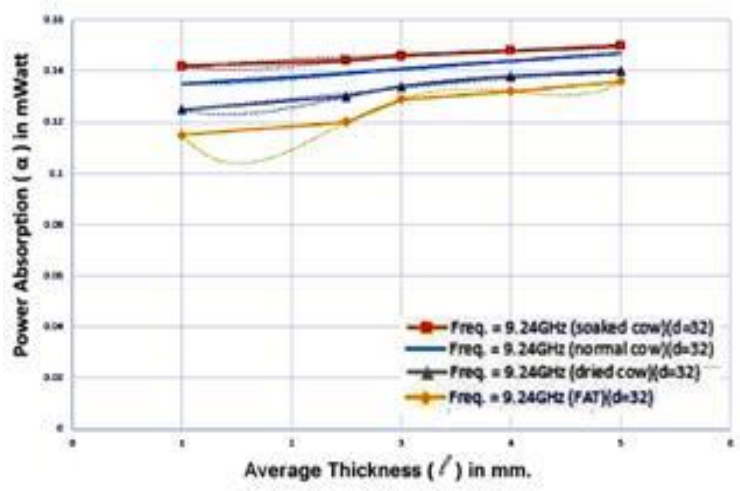

Figure 12. Power absorption for beef and fat at $9.24 \mathrm{GHz}$ and $\mathrm{d}=32 \mathrm{~cm}$ 


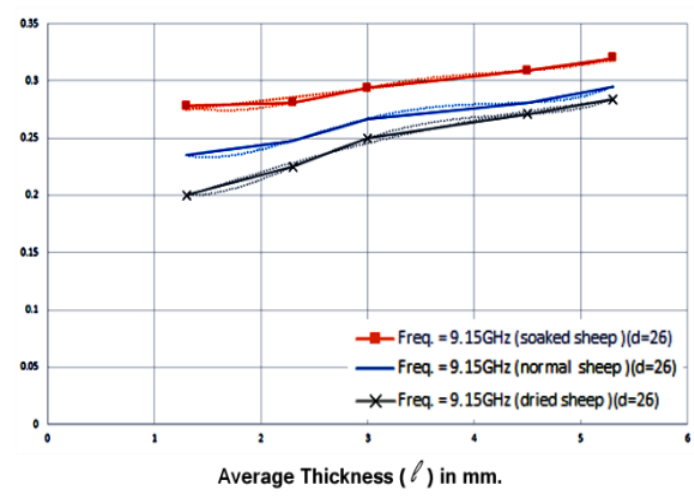

Figure 13. Power absorption for lamb at $9.15 \mathrm{GHz}$ and $\mathrm{d}=26 \mathrm{~cm}$

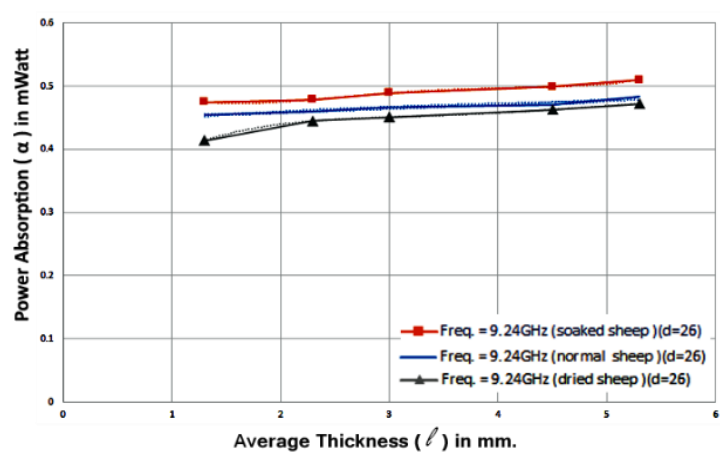

Figure 15. Power absorption for lamb at $9.24 \mathrm{GHz}$ and $\mathrm{d}=26 \mathrm{~cm}$

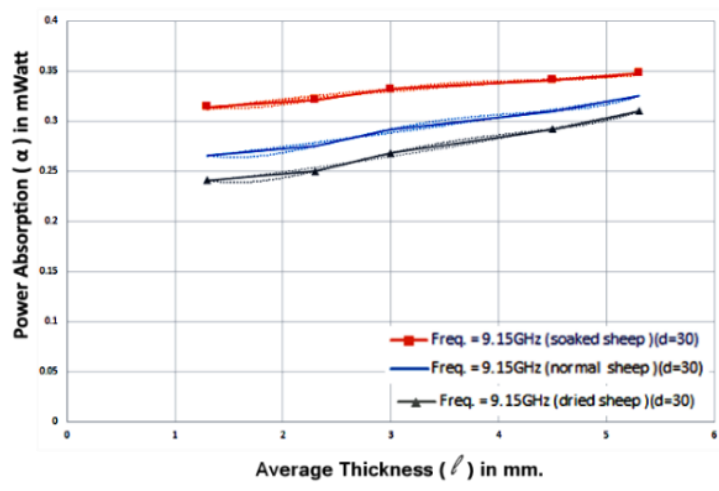

Figure 14. Power absorption for lamb at $9.15 \mathrm{GHz}$ and $\mathrm{d}=30 \mathrm{~cm}$

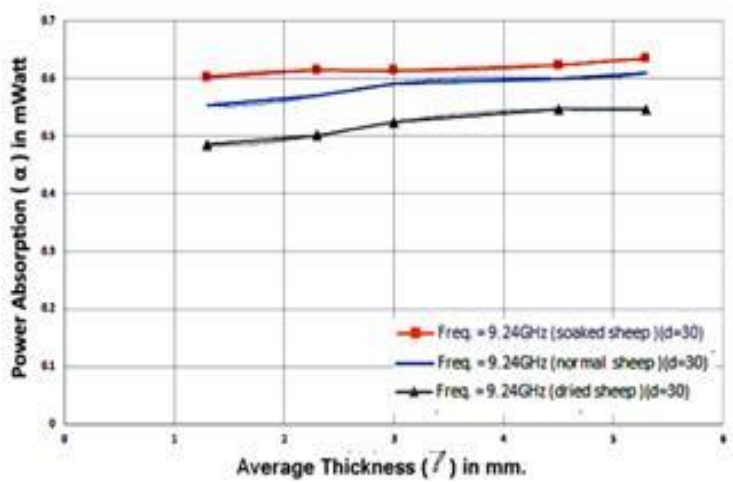

Figure 16. Power absorption for lamb at $9.24 \mathrm{GHz}$ and $\mathrm{d}=30 \mathrm{~cm}$

\section{CONCLUSIONS}

In this paper, a study of microwave power absorption in real tissues using cow meat (beef), sheep meat (lamb) and fat in range of thicknesses $(1 \mathrm{~mm}$ to $5 \mathrm{~mm}$ ) is practically investigated. It was found that, the power absorption increases with the increasing of specimen thicknesses. Moisture content (water content) with three cases normal, soaked and dried was also found to have a great impact on the microwve power absorption. Hence, the relationship between the water content and the power absorption is a directly proportional. The results of the test showed a curve plot with a clear indication shown in the case of the soaked meat (beef and lamb) as the most power absorbing case when compared to the other cases due to their high water content. The natural meat are in the middle of the graph and in the end comes the dried meat where the value of power absorption is low due to its low water content. Consequently, the results of FAT tissues show that the value of power absorption is very low as it is closer to insulation behavior because it does not contain a blood circulation as well as its very low water content.

Additionally, relation between power absorption and distance between transmitter antenna and receiver antenna at fixed frequency was also studied. This research work was applied on all samples types, and it was found that the absorbed energy increases with increasing distance because the power received is low due to the attenuation.

\section{REFERENCES}

[1] A. Alhegazi1, Z. Zakaria2, N. A. Shairi3, T. Sutikno4, R. A. Alahnomi5, and A. I. Abu-Khadrah, "Analysis and Investigation of a Novel Microwave Sensor with High Q-Factor for Oil Sensing", Indonesian Journal of Electrical Engineering and Computer Science, 2018 12(3) pp. 1407-1412.

[2] R. H. Thaher, "Biological Effects and Health Risks of Mobile Communication," International Journal of Research in Wireless Systems (IJRWS), 2009, PP. 279-286. 
[3] S. R. Abdul Mutalik, M. H. Mat, M. Jusoh, and A. W. N. Husna, " A study of specific absorption rate in human head due to electromagnetic exposure to 4G signals", Indonesian Journal of Electrical Engineering and Computer Science, 2019, 13 (3), pp. 1161-1166.

[4] John M. Williams, "Biological Effects of Microwaves: Thermal and Nonthermal Mechanisms, A Report by an Independent Investigator,"2016 Biological Thermal and Nonthermal Mechanisms, Wilsonville, Oregon, 2017, Vol 4(7), pp. 1-49.

[5] D. Razansky, D. F. Soldea, G. Yankilevich and P. D. Einziger, "Estimates on electromagnetic power absorption in highly-lossy configurations," 2004 23rd IEEE Convention of Electrical and Electronics Engineers in Israel, Tel-Aviv, Israel, 2004, pp. 193-196.

[6] R. Zaridze et al., "Electro-thermal computational suit for investigation of RF power absorption and associated temperature change in human body," 2005 IEEE Antennas and Propagation Society International Symposium, Washington, DC, 2005, vol. 2(B), pp. 796-799.

[7] R. Kubacki and J. Sobiech, "The Investigation of Specific Absorption Rate of Microwaves in the Range of Mobile and Radar Devices by Young and Mature Mice," 2006 International Conference on Microwaves, Radar \& Wireless Communications, Krakow, 2006, pp. 451-454.

[8] B. Noureddine, M. Mohamed, and K. Smain, Attenuation in Transferred RF Power to a Biomedical Implant due to theAbsorption of Biological Tissue,", World Academy of Science, Engineering and TechnologyInternational Journal of Biomedical and Biological Engineering, 2007 Vol1(10), pp. 758-761.

[9] A. Hennig, G. vom Bogel, "Analysis of Power Absorption by Human Tissue in Deeply Implantable Medical Sensor Transponders," Advanced Microwave Circuits and Systems, Vitaliy Zhurbenko, 2010, pp. 401-420.

[10] G. Gavriloaia, G. Serban, E. Sofron, M. Gavriloaia and A. Ghemiogean, "Evaluation of microwave electromagnetic field absorbed by human thyroid gland," 2010 IEEE 16th International Symposium for Design and Technology in Electronic Packaging (SIITME), Pitesti, 2010, pp. 43-46.

[11] A. Elkady, M. El-Hadidy, A. Medhat, A. Khorshid, and A. Darwish, "Microwave Power Absorption in Human Body for Non-invasiveGlucose Monitoring," Progress In Electromagnetics Research Symposium Proceedings, Stockholm, Sweden, Aug. 12-15, 2013, pp. 109-113.

[12] W. Zhi, L. Wang, and X. Hu, "Recent advances in the effects of microwave radiation on brains", Zhi et al. Military Medical Research (2017), 4(29), pp. 1-14.

[13] R. H. Thaher, and Z. S. Jamel, "New design of dual-band microstrip antenna for Wi-Max and WLAN applications," 2018 1st International Scientific Conference of Engineering Sciences - 3rd Scientific Conference of Engineering Science (ISCES), Diyala, 2018, pp. 131-134.

[14] R. H. Thaher, and N. B. Hassan, "Proposed P-shaped Microstrip Antenna Array for Wireless Communication Applications," TELKOMNIKA Telecommunication, Computing, Electronics and Control, Inodnesia, 2018, Vol 16(6), pp. 2864-2870.

[15] R. H. Thaher and S. N. Alsaidy, "Design and fabrication of new diamond patch antenna for wireless communications, " 2016 Al-Sadeq International Conference on Multidisciplinary in IT and Communication Science and Applications (AIC-MITCSA), Baghdad, 2016, pp. 1-6.

[16] Ahmed El Hamraoui, and et al.," A New Compact CPW-Fed Dual-Band Monopole Antenna for RFID Applications", Indonesian Journal of Electrical Engineering and Computer Science, 2017, 8 (1), pp. 69-76.

[17] A. K. Jassim, R. H. Thaher, "Design and Analysis of Broadband Elliptical Microstrip Patch Antenna for Wireless Communication," TELKOMNIKA Telecommunication, Computing, Electronics and Control, Inodnesia, 2018, Vol 16(6), pp.2864-2870.

[18] D. Colombi, B. Thors, C. Törnevik and Q. Balzano, "RF Energy Absorption by Biological Tissues in Close Proximity to Millimeter-Wave 5G Wireless Equipment," in IEEE Access, vol. 6, pp. 4974-4981, 2018.

[19] Ahmed El Hamraoui, and et al.," A New Compact CPW-Fed Dual-Band Monopole Antenna for RFID Applications", Indonesian Journal of Electrical Engineering and Computer Science, 2017, 8 (1), pp. 69-76.

[20] R. H. Thaher and H. Hadi Ali, "Microwave Power Absorption Evaluation of Micro-Particles Cuo Filler Reinforced Epoxy Composites," 2018 International Conference on Advanced Science and Engineering (ICOASE), Duhok, 2018, pp. 221-226. 